Are You for Real? Exploring Language Use and Unexpected Process Questions Within the Detection of Identity Deception

Louise Marie Jupe*

Aldert Vrij

Sharon Leal

Department of Psychology, University of Portsmouth, UK

Galit Nahari

Department of Criminology, Bar-Ilan University, Israel

*Address for correspondence: Louise Jupe, Department of Psychology, University of Portsmouth, King Henry Building, King Henry I Street, Portsmouth, PO1 2DY. UK. louise.jupe@ port.ac.uk. T: +44 23928466 


\begin{abstract}
The current study was to test whether Reality Monitoring and language use could distinguish identity liars from truth tellers when answering outcome questions and unexpected process questions. Truth tellers $(n=30)$ and liars $(n=30)$ discussed their identity in a recruitment interview. No differences emerged between truth tellers and liars in the details they provided. In terms of language use, liars used more positive language than truth tellers, whilst truth tellers used more cognitive process words than liars. However, neither were more pronounced when asking process questions. Overall, process questions elicited more cognitive process and cause words than outcome questions. Therefore, process questions may be able to contribute to the cognitive load approach. The findings suggest that Reality Monitoring may not be diagnostic when applied to identity deception. We discuss the language use differences in relation to Impression Management theory.
\end{abstract}


Are You for Real?

Exploring Language Use and Unexpected Process Questions Within the Detection of Identity Deception

False identities have been acknowledged as a significant contributor to the catastrophic terrorist attacks of 9/11 (Lowe, 2006; Salter, 2004). Yet the enhanced quality of falsified documents and passports has meant that their identification is becoming progressively challenging (Zill, 2002) and, as such, it presents as a national security risk (Sirotich, 2007; Barber, 2015). It is thus deemed necessary to implement further protocol to be able to identify individuals using a false identity.

Whilst telling lies is often thought to be relatively easy, the detection of these lies is difficult (DePaulo, 2018). On average, lie detection accuracy rarely exceeds that of chance level, even amongst perceived experts within the field (DePaulo \& Pfeifer, 1986; Ekman \& O’Sullivan, 1991; Kraut \& Poe, 1980; Vrij, 2008). Whilst deception research initially concentrated on non-verbal behaviours, evidence has suggested that of the very few cues associated deception, these are usually only weakly correlated and unreliable (DePaulo et al, 2003). Our current understanding from research is that by using theory-based interview techniques, an increase can be seen in the discrimination ability of investigators to identify differences between the verbal accounts of truth tellers and liars (Vrij, 2008; Vrij \& Granhag, 2012). For example, the verbal output of liars is often shorter than that of truth tellers (Kraut, 1978; Sporer \& Sharman, 2006) and truth tellers often include more detail than liars (Vrij, 2008; 2015). This can be explained by the complexities involved in telling a lie. The cognitive lie detection approach (Vrij, Fisher, \& Blank, 2017) theorises that lying is more difficult than truth telling (Zuckerman, DePaulo, \& Rosenthal, 1981). In addition, by strategically making the task of lying more difficult, verbal cues to deceit can be magnified (Vrij et al., 2017). There are three main methods which contribute to the cognitive load 
approach: (i) imposing cognitive load, (ii) asking the interviewee to say more and (iii) unexpected questions (Vrij et al., 2017). In the current study, we utilised the unexpected questions element of the cognitive lie detection approach (Lancaster, Vrij, Hope, \& Waller, 2013; Vrij, Fisher, Mann, \& Leal, 2008).

\section{Lying about Identity}

Whilst deception detection is heavily dominated by 'police-suspect' interviews whereby individuals lie or tell the truth about a transgression (Vrij \& Granhag, 2014), DePaulo and Bond (2012) have highlighted that many individuals lie about their identity. The study of identity deception is highly underrepresented within the deception literature and with increasing numbers of false documents leading to a passport fraud 'epidemic' (Paravicini, 2016), the mere examination of identity documents is not a strong enough security measure when dealing with identity fraud. Interpol (2018) reported that from January to September in 2016, their Stolen and Lost Travel Documents database (SLTD) was searched 1.2bn times, resulting in identification of 115,000 positive responses or 'hits'. Whilst this number represents when a document has been questioned in terms of its authenticity, the number of falsified documents which are not questioned (due to the quality of falsified documents), and in circulation, is difficult to quantify.

Research highlights online tools to identify online identity theft and fraud (e.g., Tan, Guo, Cahalane, \& Cheng, 2016; Thakur, 2017), but the study of the identity deceiver's verbal characteristics in face to face scenarios is negligible. What may contribute to the lack of research within identity deception is that identity is complex and can be viewed as both domain-specific and global (Goosens, 2001). Domain-specific identity relates to the unique components of our identity, such as education, occupation, demographics, experiences and autobiographical memory. Global identity is an ideological identity; the way we are viewed as a singular entity, as a combination of each of the elements of our domain-specific identity. 
In terms of domain-specific identity deception, scholars have investigated the lies people tell about their autobiographical memories (Elntib, Wagstaff, \& Wheatcroft, 2015; Sartori, Agosta, Zogmaister, Ferrara, \& Castiello, 2008), occupation (Jupe, Vrij, Leal, \& Mann, 2016; Vrij, Mann, Leal, \& Fisher, 2012), experiences (Masip, Sporer, Garrido, \& Herrero, 2005; Sporer \& Sharman, 2006), opinions (Leal, Vrij, Mann, \& Fisher, 2010) and intentions (Ask, Granhag, Juhlin, \& Vrij, 2013; Vrij, Leal, Mann, \& Granhag, 2011; Warmelink, Vrij, Mann, Jundi, \& Granhag, 2012). However, we are not aware of any published research that looks at individuals who lie about their global identity. In the current study, we aimed to combine questions from different domain-specific areas and autobiographical memories into one single interview, with the aim of gaining insight into how individuals who have to lie about many different elements of their identity (forming their global identity) differ from identity truth tellers. What is novel in the current study is that instead of merely looking at the way individuals respond to questions related to their passport, we aim to ask question which are both unrelated and unexpected as a way of eliciting differences in their verbal responses. This is in addition to allowing participants a week to prepare after being given a false identity (liars only).

In comparison with a transgression related police-suspect style interview, an individual who lies about his/her global identity no longer has to fabricate an account of what s/he did, but, instead, has to fabricate a story about whom s/he is (Jupe et al., 2016). This includes combining a variety of domain-specific elements into one global set of responses, including episodic memories. Lying individuals, however, have to not only manage their responses to deceptive episodic memories, but also align these responses to those which are more identity related. We imagine that this process will be more cognitively demanding than when individuals are only asked to lie about domain-specific elements. In addition, all individuals have an identity which they can relate to and which they have built over time. In 
contrast, not all individuals have committed a crime. Therefore, the notion of lying about identity relates to lying about something we have all experienced, rather than something we have not. It is how an individual can manipulate this overriding experience into that of an alternative identity in terms of language use and detail, which is of interest in the current study.

The ways in which individuals deceive in terms of their identity within law enforcement was addressed by Wang, Chen and Atabakhsh (2004), who examined criminal records database information. They found that to avoid initial prosecution, individuals would manipulate their identity via various strategies such as their name spelling variation, using similar pronunciations, name abbreviations, middle name swapping, and amending their residency, date-of-birth and social security number. Although the study highlighted tactics used by individuals to 'beat the system' in terms of database entries, it did not provide insight into verbal differences between identity truth tellers and deceivers during an interview. It also does not reflect how individuals who perhaps enter through borders on false security documents would be identified. If an individual were to enter the country on a falsified document, including only subtle changes to their passport information, the individual is unlikely to flagged by a computerised system. This is even less likely when actual documents are used especially as there is no EU/worldwide system for document inspection (Ensor, 2017). The current research therefore aims to look beyond the digital information relating to an individual's identity and examines the level of detail provided in verbal accounts of individuals who are asked to lie or tell the truth about who they are.

\section{Asking the Unexpected}

The unanticipated question approach introduced by Vrij et al. (2009) is derived from the notion that liars typically prepare themselves for interviews by formulating answers to anticipated questions (Granhag, Stromwall, \& Jonsson, 2003; Vrij, Mann, Leal, \& Granhag, 
2010). This is an effective strategy as prepared lies are harder to detect than spontaneous lies because they contain fewer cues to deceit (DePaulo et al., 2003; Vrij, Taylor, \& Picornell, 2015). We provide a short synopsis of the current unanticipated approach to lie detection. Asking unexpected questions was tested as a way of eliciting non-verbal leakage and revealing information by Burgoon, Buller, Ebesu and Rockwell (1994). Burgoon and colleagues demonstrated that novices (those assumed to have no prior interviewing experience) had greater level of deception detection accuracy when using unexpected questions than when using repeated or rehearsed questions. Expected questions (those which may have been planned for) are likely to reduce a liar's cognitive load, whilst unexpected questions are likely to increase a liar's cognitive load (Vrij, 2015). It is expected, therefore, that verbal outputs to unexpected questions are likely to differ between liars and truth tellers. Liars will not have prepared answers to questions which are unexpected. Therefore, when answering unexpected questions, differences between truth tellers and liars may emerge, such as truth tellers reporting more details than liars (Lancaster et al., 2013; Shaw et al., 2013; Warmelink, Vrij, Mann, \& Granhag, 2013) and more indicators of planning type behaviours (Mac Giolla, Granhag, \& Liu-Jönsson, 2013; Sooniste, Granhag, Knieps, \& Vrij, 2013; Vrij, Granhag, Mann, \& Leal, 2011).

Unexpected approaches can also include the 'devil's advocate' approach, in which interviewees are asked to generate opinions in opposition of their own (Deeb et al., 2018; Leal, Vrij, Mann, \& Fisher, 2010). Generating answers in line with one's own views is deemed less cognitively demanding than having to generate views which do not align themselves with one's own ideological views and values. Individuals asked to verbalise opinions which do not align with their own views will need to use a dual monitoring approach; that is being aware of one's own opinions whilst verbalising opinions which are in contrast. Unexpected questions also include the use of drawings during an interview 
(Hjelmsäter, Öhman, Granhag, \& Vrij, 2014; Vrij, Mann, Leal, \& Fisher, 2012). After responding to an unexpected question, the same question is then repeated but the participant is asked to respond using a different modality; that of a drawing. As liars' memory of their answers is likely to be more unstable than that of a truth tellers (Vrij, 2015), there is likely to be more inconsistencies between their verbal output and that of their drawing (Fisher, Vrij, \& Leins, 2013).

There are theoretical justifications as to why unexpected questions are harder to answer for liars than expected questions. Sporer and Schwandt (2006) propose a Working Memory Model of deception which stems from Baddeley's (1983) Working Memory theory. Whilst a truth teller can answer unexpected and expected questions from the same episodic memory, a liar is unable to recite a practiced narrative in their answers to unexpected questions. They must therefore think of answers on the spot which places a strain on working memory. As such, their verbal responses are affected and are more likely to show cues to deceit, one of which is to include less detail in their answers. Truth tellers, however, are not affected by the additional load of an unexpected question. It is therefore reasonable to expect that liars will be able to give more detail to expected questions than to unexpected questions; and this includes being able to give more detail than truth tellers to expected questions due to the element of rehearsal, and thus ease of access to the fabricated memory/answer. This supposition was supported by Lancaster et al. (2013) and Shaw et al. (2013).

In the current study, we aim to specifically study the utility of asking unanticipated 'process' questions to magnify verbal credibility cues and compare their utility to those of 'outcome' questions. Process and outcome questions are tailored around the developmental progression of a specific act. Process questions are more specific to the planning phase or the progressional experience of an event as opposed to the outcome of an event (Vrij, Mann, Leal, Vernham, \& Vaughan, 2016). For example, 'What is the purpose of your visit to 
London?', is an outcome question whilst 'How did you plan your trip to London?' is a process question. The use of process questions relating to the planning of an act stems from research which looked at planned intentions (Mac Giolla et al., 2013; Sooniste et al., 2013; Vrij et al., 2011). Truth tellers were more likely to refer to the planning stage of their intentions than liars. Truth tellers, who have experienced the progression of a true act, were able to draw on memory to answer questions regarding the processes involved in that act.

The preparation for anticipated questions in relation to identity has relevance to significant security and terrorist operations. The Manchester Manual, a computerised file found by the Metropolitan Police in 2000 in the house of an al-Qaeda member, was a 179page document containing so-called training information for Jihadist fighters. It also contained information on the need for forged identity documents, such as passports and identity cards, the learning of the information on these forged documents, to avoid travel to the location of the country the forged passport was deemed to be issued by, counterfeit currency and changes to facial appearance. It also provided a list of questions, deemed as 'anticipated', that an individual would need to be prepared to answer if being interrogated prior to, during and upon arrival at their travel destination. These questions predominantly related to the outcome of the travel and did not focus on planning or process questions. They included reasons for travel (outcome), the length of the travel period (outcome), who they would meet at the travel destination (outcome), what they would be doing at the travel destination (outcome) and who they would be staying with (outcome). One question - how one obtained the money for travel - could be deemed a process/planning question. The strategies shown here suggest that by manipulating the overriding expectation of outcome based questions being asked, verbal differences between identity truth tellers and liars may occur.

\section{Reality Monitoring}


In the current study, participants are asked to lie or tell the truth about who they are, by answering questions related to past experiences. That is, we asked liars to create a series of false events that they have experienced. Lying about identity also involves lying about the past; essentially as identity is an accumulation of past events and liars are required to lie about the experiences they have endured. The current study aims to analyse the responses provided by the participants with Reality Monitoring (RM) by coding for spatial, temporal and perceptual information. RM is not a veracity detection tool, but a method of assessing the cognitive processes that are used when discriminating between external or perceptual sources and internal or imagined events (Johnson \& Raye, 1981). The predominant aspect of RM is that the quality of details within actual perceived events and those which are imagined will vary (Vrij, 2008). RM stems from early methods of reality testing and memory monitoring. Reality testing generally refers to distinction between a present perception from a present act of remembering or imagination as described by Cameron and Carmichael (1963). It has links to clinical issues by looking as the real and the imagined in disorders such as schizophrenia (Johnson \& Raye, 1981). Reality monitoring, however, looks at distinguishing a past perception or imagination from a present one. The underpinning of Johnson and Raye's (1981) paper is that the act of experiencing an event is done so through a perceptual experience, and thus accounts of real events are more likely to be made up of details regarding: sensory perceptions; taste, smell, touch, visual and auditory information, contextual information; spatial information about the visual aspects of the experience (where it happened and where items and people were in relation to each other), temporal information; information about the order of events and their timings, and affective information; information regarding the individuals feelings during the event. The main difference between a real and imagined event is that an imagined event is more likely to consist of cognitive operations; explanatory thoughts and reasoning ("I found the phone in 
my bag upon arriving home, so I must have picked it up from the table") and as such concrete operations are often vague (Vrij, 2008). Research has supported the theoretical component to RM suggesting that reality and imagination-based memories are stored differently, with real memories including more sensory information (Gordon, Gerrig, \& Franklin, 2009). Researchers have explored whether RM can be used as a lie detection method. The assumption behind this is that an imagined event represents the situation for liars. Research has tried to identify if there are RM attributes which can be used to discriminate between truths and lies, yet standardised criteria for use with RM has yet to be established (Vrij, 2015). Particular support has, however, been found with relation to particular aspects of the RM approach, with a review of 30 laboratory studies (Vrij, 2008) suggesting that truth tellers provide more temporal, spatial and perceptual information than liars. An overview of the RM literature by Masip, Sporer, Garrido and Herrero (2005) showed that RM was able to discriminate between liars and truth tellers above that of chance level. RM has also been shown to be an effective addition to the cognitive interview (Logue, Book, Frosina, Huizinga, \& Amos, 2015) and as a way of distinguishing between actual and imagined autobiographical events (Sporer \& Sharman, 2006).

Based on the existing literature, we hypothesised that truth tellers would provide more perceptual, spatial and temporal details their answers overall than liars (Hypothesis 1). We further hypothesised that truth tellers would provide more perceptual, spatial and temporal details in their answers to process questions than liars (Hypothesis 2).

\section{Exploratory Analysis: The Language of the Liar}

Briefly touching on a sociological approach, Mead (1967) proposed the individual we are is formed through language, communication and interaction with others. Truth tellers have a lifetime of experience in relation to their identity and the language used as part of that 
process, whilst liars do not. It is hoped that these differences can be used to discriminate liars and truth tellers when investigating their language use regarding their identity.

We focused on language use which has been shown to have diagnostic value when differentiating between liars and truth tellers in other deception scenarios. Truth tellers use more positive emotion words when describing autobiographical events, because such events tend to be positively biased (Walker, Vogl, \& Thompson, 1997). The fading-affect bias (Walker, Skowronski, \& Thompson, 2003) suggests that negative memories fade faster, reducing the number of negative emotions displayed within truthful discourse of such events. Negative emotion words have been associated with shame or guilt (Ekman,1988, 2009; Vrij, 2008) and are thus more likely to be used by liars. When an individual is asked to respond to a question that is cognitively demanding, it is often reflected in the words they use. As lies are deemed cognitively more demanding than truth telling (Vrij et al., 2008; Vrij et al., 2017) we often see an increase in words associated with cognitive load in liars as opposed to truth tellers, including cognitive process words (e.g., cause, know, ought) and cause words (e.g., because, effect, hence) [DePaulo et al., 2003; Pennebaker \& Chew, 1985; Sporer \& Schwandt, 2006, 2007]). A meta-analysis from 44 studies in which software had been used to identity linguistic markers showed that liars experienced an increase in cognitive load, expressed more negative emotions and referred less to cognitive processes (Hauch, BlandónGitlin, Masip, \& Sporer, 2015).

However, these findings were obtained in a forensic domain; that is, during policesuspect style interviews. In the current study, we did not ask individuals to lie about a transgression, but asked them to lie about a much larger aspect; who they are and experiences that contributed to who they are. Individuals who lie about their identity in an employment interview may adopt Impression Management (IM) tactics to convince an interviewer of their veracity (labelled persuasive deception by Dunbar et al., 2014). That is, they will manipulate 
their language not only to convince the interviewer of their honesty, but also to convince the interviewer about their likeability and suitability for the role in question. This is achieved through interpersonal interaction and communication between the interviewer and the interviewee. Research has shown that almost all interviewees overemphasise their positive attributes and de-emphasise negative ones (e.g., Donovan, Dwight, \& Hurtz, 2003; Jansen, König, Stadelmann, \& Kleinmann, 2012). In addition, deceptive individuals have been shown to strategically mask any associated feelings of shame or guilt with the use of positive language (Buller \& Burgoon, 1996). Research by Zhou, Burgoon, Nunamaker and Twitchell (2004) used LIWC to analyse verbal differences between truth tellers and liars. Whilst they found no multivariate effect of affect, follow up analyses showed that liars used more positive affect than truth tellers. Research conducted by Burgoon et al., (2015) showed that when conference calls were analysed, unscripted answers were higher in positive emotion words than when the answers were scripted. Therefore, the answers which were prepared in advance, contained fewer positive emotion words than unprepared answers. In addition, using a corpus of thirty-two native American English speakers, LIWC indicated that of the possible 68 categories examined, positive emotions words were the most indicative of deception (Hirschberg et al., 2005; cf. Newman, Pennebaker, Berry, \& Richards, 2003).

Due to the current study's paradigm of a recruitment style interview, we expect to see liars to use language to their advantage and presenting themselves more positively than truth tellers, by using more positive emotion words (e.g., love, sweet, nice) (Hypothesis 3). We also expect to see less negative language used by liars than truth tellers (e.g., hurt, ugly, nasty) in an attempt to distance themselves from their deception (Hypothesis 4). In addition, we expect that differences will be amplified by the use of process questions. We predict that liars will manage their impressions by decreasing negative words for questions which are unexpected, so that they are used less often than by truth tellers, to compensate for the 
increasing difficulty in answering the question (Hypothesis 5). We also expect liars to use more positive words than truth tellers for process questions (Hypothesis 6), again in an attempt to manage the impressions they exhibit during questioning.

In the current study, we also wish to explore how asking unanticipated process questions affects the use of cognitive process words and cause words. Whilst leading theoretical underpinnings of deceptive behaviour are often explained in terms of cognitive load (Vrij, Fisher et al., 2008), such findings are specific to police-suspect scenarios. That is, during previous police-suspect scenario interviews, it is the individual's involvement in a transgression that is under question. In the current study, we ask liars not to deny their involvement in a crime, but to lie about who they are. Whilst we suspect that there will be a difference between liars and truth tellers in their use of cognitive process and cause words, there is not enough existing literature to be able to draw a clear prediction in which direction such a difference will be observed; that is, the level of cognitive load experienced by identity deceivers is unexplored within deception literature. We therefore expect to see a difference between truth tellers and liars in terms of cognitive process words (Hypothesis 7) yet remain non-directional in such a prediction. The same is also true for cause words. Whilst we expect to see a difference between truth teller and liars in terms of cause words (Hypothesis 8), we are not able to predict if this will be higher for liars or truth tellers. If a difference is observed, we will use exploratory analysis to see how such differences occur between process and outcome questions and if such differences appear from a main effect of Veracity or Question Type (process versus Outcome).

\section{Method}

\section{Participants}

A total of 60 participants, comprising of 23 males and 37 females, aged between 18 and 68 years $(M=25.10 . S D=10.22)$ with a median age of 21 years were recruited from the 
University of Portsmouth's student $(n=52)$ and staff $(n=8)$ population. No participants were excluded from the study, and thus all data was included.

\section{Design}

The current study used a mixed design with Veracity (truth versus lie) as the betweensubjects factor and the Question Type (outcome versus process) as the within-subjects factor. Total detail, perceptual detail, temporal detail, spatial detail, positive emotion words, negative emotion words, cognitive process words and cause words were the dependent variables.

\section{Procedure}

Participants were recruited via internal advertising university webpages and online participant pool. Participants were informed that the study would consist of a recruitment style interview for a fictitious job position, and that they would attend either truthfully as themselves or assuming the identity of somebody else. Seven days before the study was due to take place, participants were emailed further information about the experiment, including their veracity status. In addition, both truth tellers and liars were given the choice of the type of position they would be applying for from the following options: (a) Journalism, (b)

Politics, (c) Music, (d) Film/Media, (e) Lecturer/Academic, (f) Veterinary/Animal Management, (g) Researcher, (h) Psychologist, (i) Medical professional and (j) Business/Executive. Both truth tellers $(n=30)$ and liars $(n=30)$ were told to think about the type of questions that may be asked during the interview and to prepare for them. However, liars were told that they must take part in the interview assuming the identity of somebody else and must not reveal their true identity to the interviewer. They were told that they were to be taking part in an undercover mission to gain access to the target organisation. They were required to obtain a position to allow them to spy on internal members of staff who are thought to be members of an extremist organisation and that their mission was to remain 
undercover. It was stressed that their answers to questions should be entirely fictitious. Truth tellers were told to be entirely truthful throughout the interview. To encourage participants to perform well, participants were told that those providing a convincing interview would be entered into a prize draw to win one of two $£ 100$ prizes.

Seven days later participants arrived at the laboratory at pre-arranged times and were asked to read over the participant information sheet and to sign the informed consent form. Participants were asked if they required any preparation time. Once the participant was ready, they were asked to complete a pre-interview questionnaire to obtain demographic information. They were also asked how motivated they were to perform well during the interview on a 7-point Likert scale ranging from [1] Extremely Unmotivated to [7] Extremely Motivated. After completion of the pre-interview questionnaire, participants were taken to be interviewed, by one of three female research assistants who were blind to the veracity status of each participant, and also to our hypotheses. Each participant, irrespective of veracity and type of position, was asked the same standardised set of questions, which included eight thematically related questions, split into an outcome and a process question. Therefore, a total of 16 questions were asked as part of the interview (see appendix A). The order of the questions remained consistent throughout. The interview was audio recorded and later transcribed.

After the interview, participants completed a post-interview questionnaire to obtain information regarding the level of truthfulness during their overall interview and the level of truthfulness to each outcome and process questions. Participants were asked to rate their truthfulness on a series of 11-point Likert scales (ranging from [0] a complete lie to [10] completely truthful). After the questionnaire was completed the participants were thanked and debriefed.

\section{Coding}




\section{RM coding.}

The interviews were transcribed and the responses were coded by a rater, blind to the veracity status of the participant. Based upon Vrij et al. (2016), perceptual information, temporal information and spatial information were each numerically coded and a total detail calculated for each participant in terms of the interview overall, and broken down into the answers to process and outcome questions. Participants answered questions pertaining to the present or future by drawing upon memories from the past. We therefore coded all responses for perceptual, spatial and temporal details.

Perceptual information relates to details that pertain to the experiences from sensory inputs such as sound (e.g., 'I heard my line manager knock on my door'), smell (e.g., 'I could smell burning from the photocopier), taste (e.g., 'I could taste lemon dish soap in my office mug), touch (e.g., 'The computer hard drive was very hot to the touch') and vision (e.g., 'I saw the job in animal management'). Spatial information relates to location information (e.g., 'I was sitting at my desk in my office') or the arrangements of objects (e.g., 'My desk was situated next to the boardroom') or people (e.g., 'My boss was stood behind me at the time'). Temporal information relates to information pertaining to the time an event occurred (e.g., 'I was in my second year at University') or to describe a sequence of events (e.g., 'After my final exam I went straight to the careers advisor').

\section{Inter-rater reliability.}

A second coder, also blind to the veracity status of the interviews, coded 12 of the 60 interviews $(20 \%)$. The inter-rater reliability scores were high: total detail, ICC $=.938$, perceptual information, ICC $=.919$, temporal information, $\mathrm{ICC}=.968$ and spatial information, $\mathrm{ICC}=.861$.

\section{Use of language.}


Each interview was separated into a single text document, with the questions and any utterances made by the interviewer removed. These files were then analysed by the computerised text analysis software LIWC (Pennebaker, Boyd, Jordan, \& Blackburn, 2015) to provide nominal counts for positive emotion words of which there are 406 words categorised (e.g., love, nice, sweet), negative emotion words of which there are 499 words categorised (e.g., hurt, ugly, nasty) cognitive process words of which there are 730 words (e.g., cause, ought, know) and cause words, which are a subcategory of cognitive process words and includes 108 categorised words (e.g., because, effect, hence). The process was then repeated but each interview was separated into two separate text documents, with the answers to outcome questions in one file and the answers to process questions in another. Again, each file was analysed with LIWC and nominal counts for positive emotion words, negative emotion words, cognitive process words and cause words.

\section{Results}

\section{Questionnaire Responses}

\section{Motivation.}

The motivation of the participants to be convincing in the recruitment interview was high $(M=5.83$ out of $7, S D=.92,95 \%$ CI $[.67,1.17])$. There was no difference between truth tellers $(M=5.70, S D=1.09,95 \% \mathrm{CI}[.67,1.46)$ and liars $(M=5.97, S D=.72,95 \% \mathrm{CI}$ $[.49, .90])$ in motivation scores, $t(58)=1.21, p=.268, d=.29$.

\section{Manipulation check.}

Truth tellers reported an overall truthfulness rating as high $(M=9.43$ out of $10, S D=$ $.68,95 \%$ CI $[.49, .80])$, whilst liars reported an overall truthfulness rating as low $(M=2.07$ out of $10, S D=2.66,95 \%$ CI $[1.17,3.00])$. This difference was significant, $t(58)=14.68, p<$ $0.001, d=3.79$. Truth tellers reported their overall truthfulness rating for outcome questions as high $(M=9.26$ out of $10, S D=.89,95 \%$ CI $[.54,1.09])$, whilst liars reported their overall 
truthfulness rating for outcome questions as low $(M=1.89$ out of $10, S D=2.32,95 \% \mathrm{CI}$ $[1.06,3.20])$. Also this difference was significant, $t(58)=16.24, p<0.001, d=4.19$. Finally, truth tellers reported their overall truthfulness rating for process questions as high $(M=8.85$ out of $10, S D=2.03,95 \% \mathrm{CI}[.76,3.18])$, whilst liars reported their overall truthfulness rating for process questions as low $(M=1.23$ out of $10, S D=2.03,95 \%$ CI $[.89,3.21])$. This difference was significant, $t(58)=14.28, p<0.001, d=3.75$. These findings support the validity of the veracity manipulation.

\section{Interview Responses}

\section{Duration.}

There was no significant difference between duration of the interviews in seconds between truth tellers $(M=951.40, S D=582.00,95 \%$ CI $[282.93,825.19])$ and liars $(M=$ 887.33, $S D=424.60,95 \%$ CI $[226.38,612.70]), t(58)=.487, p=.628, d=.13$.

\section{Word count.}

There was no significant difference for word count between truth tellers $(M=$ 1629.20, $S D=1049.82,95 \% \mathrm{CI}[625.64,1363.22])$ and liars $(M=1604.10, S D=1035.60$, $95 \%$ CI $[428.77,1533.52]), t(58)=.093, p=.926, d=.02$.

A one-factor between subjects MANOVA was conducted with Veracity (truth versus lie) as the only factor, and, total process question word count and total outcome question word count as the dependent variables. The MANOVA revealed no significant multivariate main effect for Veracity, Wilks' $\lambda=.957, F(2,57)=.733, p=.485, \eta p 2=.025$. In addition, no significant univariate main effects were obtained for any of the two dependent variables, all $F$ 's $<.94$, all $p$ 's $>.761$ (see Table 1).

\section{RM Detail}

A 2 x 2 mixed-design MANOVA was conducted with Veracity (truth versus lie) as the between-subjects factor, Question Type (process versus outcome) as the within-subjects 
factor, and (i) perceptual detail, (ii) spatial detail and, (ii) temporal detail as the dependent variables. The MANOVA revealed no significant main effect for Veracity, Wilks' $\lambda=.899$, $F(3,54)=2.012, p=.123, \eta p^{2}=.101($ see Table 2$)$. Hypothesis 1 is therefore not supported. The MANOVA revealed a significant main effect for Question Type Wilks' $\lambda=.771, F(3$, $54)=5.348, p=.003, \eta p^{2}=.229$. A significant univariate effect was obtained for one of the three dependent variables. Answers to process questions contained significantly more perceptual detail than for outcome questions (see Table 3). There was no Veracity X Question Type interaction, $\lambda=.974, F(3,54)=.477, p=.700, \eta p^{2}=.026$. Hypothesis 2 is therefore not supported.

\author{
[Insert Table 1 about here] \\ [Insert Table 2 about here] \\ [Insert Table 3 about here]
}

\title{
Exploratory Analysis
}

\section{Use of Language}

A 2 x 2 mixed-design MANOVA was conducted with Veracity (truth versus lie) as the between-subjects factor, Question Type (process versus outcome) as the within-subjects factor, and (i) positive emotion words, (ii) negative emotion words, (iii) cognitive process words, and (vi) cause words as the dependent variables. The MANOVA revealed a significant main effect for Veracity, Wilks' $\lambda=.806, F(4,55)=3.307, p=.017, \eta p^{2}=.101$. Significant univariate effects for Veracity were obtained for two of the four dependent variables. Liars used significantly more positive emotion words than truth tellers. In addition, truth tellers used significantly more cognitive process words than liars (see Table 4). Hypothesis 3 and 7 are therefore supported, whilst there is no support for Hypothesis 4 and 8 . The MANOVA revealed a significant main effect for Question Type Wilks' $\lambda=.554, F(4$, $55)=11.079, p<.001, \eta p^{2}=.446$. Significant univariate effects for Question Type were 
obtained for all of the dependent variables. Positive emotion words were used significantly more in response to outcome questions than to process questions. Negative emotion words were also used significantly more in response to outcome questions than to process questions. Cognitive process words occurred significantly more in response to process questions and cause words appeared significantly more in response to process questions than to outcome questions (see Table 5). There was no Veracity X Question Type interaction, $\lambda=.864, F(4$, $55)=.2 .171, p=.084, \eta p^{2}=.136$. Hypothesis 5 and 6 are therefore not supported.

[Insert Table 4 about here]

[Insert Table 5 about here]

\section{Power}

A power analysis using G*Power (Faul, Erdfelder, Lang, \& Buchner, 2007) and using MANOVA for repeated measures with within-between interactions, indicates that for a large effect size $f(V)=0.8, \alpha=0.05$, with two groups, a sample size of 28 (14 per cell) would be sufficient for a power of 0.95 , when measuring three response variables. Three response variables pertain to the RM MANOVA calculations. For the LIWC MANOVA analyses, with the same power and alpha thresholds, four response variables would require a total sample size of 32 (16 per cell). However, there is a wide range effect sizes within the deception literature. For example, based upon the median effect of .10 for deceptive cues as per the seminal paper by DePaulo et al., (2003), to obtain a sufficient power of 0.8 , with $\alpha=0.05$, two groups and three response variables, the total sample size would need to be 1548 (774 per cell), or 1721 (860 per cell) for four response variables. However, DePaulo et al., (2003) was predominantly based upon non-verbal cues to deception, whilst the current paper investigated verbal cues. In comparison, verbal veracity studies using unexpected questions have shown larger effect sizes (i.e., .79, [Vrij et al., 2018]). These overall power calculations 
were made after the study was conducted. Of course, such large sample sizes have not been used in deception experiments to date and would actually make running studies unfeasible.

\section{Discussion}

\section{Reality Monitoring}

In the current study, we predicted that the answers to process questions would elicit more cues to deceit amongst liars than outcome questions in terms of RM detail. We found no difference in the detail given by truth tellers and liars in their answers to process and outcome questions, nor in their answers overall. Although these findings are not supported by existing literature, we suggest a number of reasons as to why this may be in the current domain of identity deception detection. First, memories for events fade over time (Murre \& Dros, 2015), and therefore so will specific details associated with these memories. Vrij (2015) states that RM is not a suitable tool for distant memories. In addition, Sporer and Sharman (2006) demonstrated that recent memories were richer in RM details than distant memories. Whilst we do not assume that all previous employment and personal experiences would have been recalled from distant memories, it is a possible explanation as to why RM was not able to distinguish between truth tellers and liars. Had these actual memories for events (for truth tellers) been from a significantly earlier time, experiential details often identified within RM may have been forgotten, narrowing the differences between truth tellers and liars.

A second reason as to why RM may not have differentiated between truth tellers and liars in the current study is preparation time. It may be that liars spent more time preparing for the identity interview than truth tellers. This of course makes sense as truth tellers were relying on their memory as opposed to their story telling abilities. This may mean that the fabricated memories of liars were quicker to access than the actual memories for truth tellers who needed to search through their internal repertoire of memories to be able to answer. If 
liars spent longer than truth tellers preparing for the interview, this may have been a contributor to liars' ability to provide numerous details. We know that liars are strategic in preparing to be interviewed in police-suspect style interviews (Bond \& DePaulo, 2006; Vrij, Mann, Leal, \& Granhag, 2010), yet we are not fully aware of the strategies of individuals who lie about their identity. Whilst it is envisaged that such strategies are likely to be somewhat similar (i.e., rehearsing answers to anticipated questions, [Granhag, Andersson, Strömwall, \& Hartwig, 2004; Hartwig, Granhag, \& Strömwall, 2007)]), further research into strategies is needed.

In addition, when a liar is aware that a detailed account is more likely to be believed, the discriminate ability of RM is reduced (McDougall \& Bull, 2015; Nahari \& Pazuelo, 2015). In lieu of their honesty, liars may have strategically included more details in their accounts. The inclusion of details in a known strategy employed by liars to appear more credible during an interview (Bell \& Loftus, 1989) and may have motivated them to provide detailed accounts. Studies have shown that statements higher in detail are more likely to be deemed as credible (Adams \& Jarvis, 2006; Bell \& Loftus, 1988). If a liar adopts the strategy of providing a statement rich in detail, the diagnostic utility of RM is reduced.

Finally, interviewees lied about their identity rather than a transgression; the typical domain in which RM deception research has been carried out. The individual who lies about his/her identity is not lying in the same way as a transgression suspect. A suspect lying about a transgression may only have a short window of time for which they need to be deceptive (e.g. the time of the transgression), whereas an identity deceiver has an exhaustive window; an entire lifetime. This may have allowed the liars to adopt strategies such as embedding lies into their own true narratives (Leins, Fisher, \& Ross, 2013) and an affluence of details may have been generated by adopting a 'story telling approach' (Jupe et al., 2016). Individuals may also describe the identity of a close friend or relative, which allows a strategy close to 
embedding and includes experiences that are obtained by somebody else. Although unique sensory details may be more often seen in spontaneous accounts in relation to a transgression (Adams \& Jarvis, 2006), liars may have found it easy to include a wide array of details from previous experiences, as a means of sensory embedding, therefore reducing the differences between truth tellers and liars. Research has shown that when liars report previous experiences, as opposed to outright fabrications, the ability of RM to distinguish between liars and truth tellers was reduced (Gnisci, Caso, \& Vrij, 2010). It seems logical that liars would adopt such a strategy.

\section{The Language of the Liar}

In the current study, we predicted that when answering process questions, liars would show differences in the type of language they use when compared with truth tellers. We did not find evidence for this. However, in line with our predictions, liars used more positive language in their interviews overall than truth tellers. Self-presentation Impression Management (IM) theories may help to explain such findings. The self-presentation model of deception (DePaulo et al., 2003) postulates that to appear credible, individuals groom their presentation to others; that is, they filter what the recipient does and does not see. By filtering negativity (in terms of negative affect) and increasing positivity (positive affect), the overall assessment of the individual is likely to be more favourable. Pro-social behaviour has been suggested as way to dissipate feelings of guilt (Freedman, Wallington, \& Bless, 1967; Staub, 1978). The use of positive language in the current study may have acted as positive selffeedback; a way of intrapersonally distancing oneself from the act of deception by speaking more positively about oneself. In addition, in line with the findings of Donovan et al. (2003) and Jansen et al. (2012), lying interviewees in the current study may have manipulated their use of positive language as a way of emphasiing their likability, reducing the liklihood of their deception being identified. Interpsersonal Deception Theory (IDT) posits that 
individuals who are able to better communicate with positive affect, are more likely to be deemed as credible (Buller \& Burgoon, 1996).

We specifically wanted to see if process questions could maginify the differences between truth tellers and liars. We did not find differences between the type of language used by liars and truth tellers when they were asked either process or outcomes questions (interaction effect). However, we did find that Question Type had an overall effect on the language used by particpants. Process questions contained less affect (positive and negative) than outcomes questions. This makes logical sense. When an individual has to think harder to answer a question, thus increasing congitive load, they may be less inclined to discuss elements of emotions such as feelings or personal states whilst they try and generate plausible answers.

We also wanted to explore the use of cognitive process and cause words by liars and truth tellers. We predicted that there would be a difference, but due to the scant literature on cognitive load in identity deception interviews, this prediction remained non-directional. We found that truth tellers used more cognitive process words than liars in their overall answers. There was, however, no difference in cause words. This finding is interesting in relation to the current relationship between deception and cognitive load (Vrij, Fisher, \& Blank, 2017; Vrij, 2015). In the current paradigm, individuals were asked questions not only about their past, but also the processes involved. The findings would suggest that truth tellers, whilst attempting to stick as close to the truth as possible, searched through memory for genuine answers to genuine problems. For example, when answering the questions 'What was the most 'difficult' social aspect of your most recent job or recent education?' and 'How did this situation evolve into being and how exactly did this incident affect your relationship with your co-workers / fellow students?', truth tellers may have worked hard to search for the exact memory of the event and the process involved, therefore using more cognitive process 
and cause words in their verbal outputs. Having to search through memory is an indication of cognitive load. Liars, on the other hand, may have recited the most logical story telling narrative which answers the question. This does not include searching through episodic memory to find an answer. It includes generating an answer which makes the most logical sense in response to the question. It may also have links with the notion of inhibition. Truth tellers may have worked harder to supress extreme negative events that they did not wish to discuss in the interview (Blandón-Gitlin, Fenn, Masip, \& Yoo, 2014). Liars do not have to do this if they adopt a story telling approach.

Whilst it has not been associated with deception detection literature previously, Zipf's Principle of Least Effort (PLE, Zipf, 2016) may allow for a possible explanation as to why truth tellers exhibited higher signs of cognitive load than liars. According to the PLE, human behaviour can be explained by efficiency law, in that people seek actions with the least effort but with maximum gain. In essence, people operate upon a cost-benefit analysis. If we apply the PLE to the current identity domain, due to the prevalence of deception in everyday discourse (DePaulo, Kashy, Kirkendol, Wyer, \& Epstein, 1996), the PLE would posit that it is in fact easier for liars, who are not hampered by memory limitations, to create a convincing story; and to tell a story 'on the fly'. Truth tellers however, will need to search through their memories to find the best, yet truthful, answer. This implies that truth tellers may face higher levels of cognitive load than liars within the current domain. This, however does not support the supposition by Burgoon (2015) on the notion of differing cognitive load depending on the discourse genre. Burgoon states that when lying about factual narratives, liars are faced with the task of monitoring which details to tell and making sure that they are plausible and coherent, whilst truth tellers are only restricted by memory. Liars may be affected by other elements of speech that were not examined in the current study, such as providing answers which are deemed plausible. However, it is widely accepted amongst the deception literature 
that events which are more recent, are easier for truth tellers to recall than those which are distant memories (Walczyk, Igou, Dixon, \& Tcholakian, 2013; Vrij, 2014; Burgoon 2015). When applied to the current study, truth tellers may have found it harder to retrieve actual memories than for liars who have recently rehearsed their own narrative. In most situations, liars have to multi-task; that is, they need to pay close attention to what they are saying verbally whilst also monitoring their impression management. In addition, they must make choices about which aspects of questions to lie about and which to not. Such dual monitoring or multi-tasking is places more strain on cognitive load (Vrij, 2015). The juxtaposition of findings suggests that there is an avenue for future research which further explores the cognitive load experienced by liars and truth tellers when discussing their identity.

In line with a supposition that liars need to dual monitor their responses, future research which asks a combined set of outcome questions first and then their associated process questions after, in a random presentation, may increase the cognitive load imposed on liars. This is in line with the suggestion that asking unanticipated questions before returning to standard questions, is more likely to elicit revealing information (Burgoon et al., 1994). This may in turn further exasperate the findings from the current study. Liars will have to try and remember their answers to many outcome questions and then simultaneously provide a plausible response to the process questions. It is envisaged that this will be a difficult task.

Limitations with regards to applying IM theory to the current research may include that of possible demand characteristics. Although research has demonstrated that transgression related lies told within the laboratory show a similar detectability rate with that of lies told in real-life forensic settings (Hartwig \& Bond, 2014), the domain of identity deception research is in its infancy. We must therefore tread cautiously. The interview within the laboratory is a social situation itself (Page, 1981), and without further research which includes strategy data, we cannot rule out that findings from the current study are in part 
related to participants preconceived ideas about the study. In addition, the findings of Burgoon and Qin (2006) suggest that there can be significant variability in the ways that individuals use verbal behaviour when lying and telling the truth across a variety of verbal measures. Such findings not only push towards an individual differences approach but may also lend support towards linguistic variations across interview contexts. Therefore, exploring linguistic variables in relation to identity, across a variety of interviewing and contextual methods is a potential avenue for future research.

In the current study, the liars' mission was to use a false identity to obtain a position of employment to allow them to spy on internal members of staff who are thought to be members of an extremist organisation. Essentially, this is a positive mission. Although those in the deceptive condition were lying, one could argue that they did so for a good cause. As their mission was to avoid rejection as a potential candidate to allow undercover operations, lying in the current context may not have created the same emotional response that is usually expected of liars (Vrij, 2008; Zuckerman, Depaulo, \& Rosenthal, 1981). This lack of anxiety may have allowed for more detailed and positive accounts. Future studies should therefore take this into account.

It is also worth noting that the current study is likely to be underpowered, and as such may have contributed to the current findings. We discussed such power calculations in the results sections. There are issues in relation to low power which should be considered when interpreting the findings from the current paper. Studies with low power relating from low sample sizes can result in both an over inflation of significant effects and a failure to detect small effects (Yarkoni, 2009). Whilst this is something to be considerate of, running highly powered studies is particularly difficult in social science research where those who participate often do so on a voluntary basis. However, as identity deception is a newly 
emerging field, we would expect findings from the current study to be replicated in future research, and that such power considerations can be taken into account.

In addition, we must take into account the paradigm in which these findings were obtained: A recruitment style interview. We asked truth tellers to be entirely honest in their interviews which was supported with manipulation checks. However, research has shown that individuals frequently lie in job applications (Reinhard et al., 2013; Weiss \& Feldman, 2006). This may indicate that participants in the truthful condition of the current study may not have been acting in a way that maps real world behaviour. Future studies may want to take into account the specific instructions given to truth tellers to yield more representative behaviour. It is also possible that liars used embedded lies in the current study (Leins et al., 2013), as per partial explanation to the RM findings. Future research should consider incorporate asking participants about their verbal strategies to identify if embedding is commonplace in identity deception.

In conclusion, the findings from the RM analysis are inconsistent with previous findings. This suggests that RM may not have diagnostic value when applied to the crosssituational domain of identity deception. The findings from linguistic analysis showed that there are significant differences in the way that truth tellers and liars manage their overall verbal outputs with regards to positive emotion language and cognitive process words. We also found that process questions appeared to elicit more cognitive process and cause words than outcome questions, suggesting that process questions are harder to answer than outcome questions. 


\section{References}

Adams, S. H., \& Jarvis, J. P. (2006). Indicators of veracity and deception: An analysis of written statements made to police. International Journal of Speech, Language and the Law, 13(1), 1-22. https://doi.org/10.1558/s1l.2006.13.1.1

Ask, K., Granhag, P. A., Juhlin, F., \& Vrij, A. (2013). Intending or pretending? Automatic evaluations of goal cues discriminate true and false intentions. Applied Cognitive Psychology, 27(2). https://doi.org/10.1002/acp.2893

Baddeley, A. D. (1983). Working Memory. Philosophical Transactions of the Royal Society B: Biological Sciences, 302(1110), 311-324. https://doi.org/10.1098/rstb.1983.0057

Barber, S. (2015). The Direct Link Between Identity Theft and Terrorism, and Ways to Stop It. Retrieved March 28, 2018, from https://news.utexas.edu/2015/12/07/the-direct-linkbetween-identity-theft-and-terrorism

Bell, B. E., \& Loftus, E. F. (1988). Degree of Detail of Eyewitness Testimony and Mock Juror Judgments1. Journal of Applied Social Psychology, 18(14), 1171-1192. https://doi.org/10.1111/j.1559-1816.1988.tb01200.x

Bell, B. E., \& Loftus, E. F. (1989). Trivial persuasion in the courtroom: The power of (a few) minor details. Journal of Personality and Social Psychology, 56(5), 669-679. https://doi.org/10.1037/0022-3514.56.5.669

Blandón-Gitlin, I., Fenn, E., Masip, J., \& Yoo, A. H. (2014). Cognitive-load approaches to detect deception: searching for cognitive mechanisms. Trends in Cognitive Sciences, 18(9), 441-4. https://doi.org/10.1016/j.tics.2014.05.004

Bond, C. F., \& Depaulo, B. M. (2006). Personality and Social Psychology Review. Personal and Social Psychology Review, 10(3), 214-234. https://doi.org/10.1207/s15327957pspr1003

Buller, D. B., \& Burgoon, J. K. (1996). Interpersonal Deception Theory. Communication 
Theory, 6(3), 203-242. https://doi.org/10.1111/j.1468-2885.1996.tb00127.x

Burgoon, J. K. (2015). When is deceptive message production more effortful than truthtelling? A baker's dozen of moderators. Frontiers in Psychology. https://doi.org/10.3389/fpsyg.2015.01965

Burgoon, J. K., \& Qin, T. (2006). The dynamic nature of deceptive verbal communication. Journal of Language and Social Psychology, 25(1), 76-96. https://doi.org/10.1177/0261927X05284482

Burgoon, J. K., Buller, D. B., Ebesu, A. S., \& Rockwell, P. (1994). Interpersonal Deception: Accuracy in Deception Detection. Communication Monographs, 61(4), 303-325.

Burgoon, J., Mayew, W., Giboney, J., Elkins, A., Moffitt, K., \& Dorn, B. et al. (2015). Which Spoken Language Markers Identify Deception in High-Stakes Settings? Evidence From Earnings Conference Calls. Journal Of Language And Social Psychology, 35(2), 123 157. http://dx.doi.org/10.1177/0261927x 15586792

Deeb, H., Vrij, A., Hope, L., Mann, S., Leal, S., Granhag, P. A., \& Strömwall, L. A. (2018). The Devil's Advocate approach: An interview technique for assessing consistency among deceptive and truth-telling pairs of suspects. Legal and Criminological Psychology, 23(1), 37-52. https://doi.org/10.1111/lcrp.12114

DePaulo, B. (2018). The Psychology of Lying and Detecting Lies. UK: Amazon.

DePaulo, B. M., \& Bond, C. F. (2012). Beyond accuracy: Bigger, broader ways to think about deceit. Journal of Applied Research in Memory and Cognition, 1(2), 120-121. https://doi.org/10.1016/j.jarmac.2012.04.010

DePaulo, B. M., \& Pfeifer, R. L. (1986). On-the-Job Experience and Skill at Detecting Deception1. Journal of Applied Social Psychology, 16(3), 249-267. https://doi.org/10.1111/j.1559-1816.1986.tb01138.x

DePaulo, B. M., Kashy, D. A., Kirkendol, S. E., Wyer, M. M., \& Epstein, J. A. (1996). Lying 
in everyday life. Journal of Personality and Social Psychology, 70(5), 979-995. https://doi.org/10.1037/0022-3514.70.5.979

DePaulo, B. M., Lindsay, J. J., Malone, B. E., Muhlenbruck, L., Charlton, K., Cooper, H., ... Cooper, H. (2003). Cues to deception. Psychological Bulletin, 129(1), 74-118. https://doi.org/10.1037//0033-2909.129.1.74

Donovan, J. J., Dwight, S. A., \& Hurtz, G. M. (2003). An Assessment of the Prevalence, Severity, and Verifiability of Entry-Level Applicant Faking Using the Randomized Response Technique. Human Performance, 16(1), 81-106. https://doi.org/10.1207/S15327043HUP1601_4

Dunbar, N. E., Jensen, M. L., Bessarabova, E., Burgoon, J. K., Bernard, D. R., Harrison, K. J., ... Eckstein, J. M. (2014). Empowered by Persuasive Deception. Communication Research, 41(6), 852-876. https://doi.org/10.1177/0093650212447099

Ekman, P. (1988). Lying a N D Nonverbal Behavior: Theoretical Issues and New Findings. Journal of Nonverbal Behavior, 12(Mh 06092), 163-175. https://doi.org/10.1007/BF00987486

Ekman, P. (1992). Telling Lies: Clues to Deceit in the Marketplace, Politics, and Marriage. Design (Vol. Paperback,). https://doi.org/152.384 E45t

Ekman, P., \& O’Sullivan, M. (1991). Who can catch a liar? American Psychologist, 46(9), 913-920. https://doi.org/10.1037/0003-066X.46.9.913

Elntib, S., Wagstaff, G. F., \& Wheatcroft, J. M. (2015). The Role of Account Length in Detecting Deception in Written and Orally Produced Autobiographical Accounts using Reality Monitoring. Journal of Investigative Psychology and Offender Profiling. https://doi.org/10.1002/jip.1420

Ensor, J. (2017, July 2). How migrants flying to western Europe raise fresh border fears. The Sunday Telegraph. Retrieved from https://www.pressreader.com/uk/the-sunday- 
telegraph/20170702/281835758720289

Faul, F., Erdfelder, E., Lang, A.-G., \& Buchner, A. (2007). G*Power 3: A flexible statistical power analysis program for the social, behavioral, and biomedical sciences. Behavior Research Methods, 39(2), 175-191. https://doi.org/10.3758/BF03193146

Fisher, R. P., Vrij, A., \& Leins, D. A. (2013). Does testimonial inconsistency indicate memory inaccuracy and deception? Beliefs, empirical research, and theory. In Applied Issues in Investigative Interviewing, Eyewitness Memory, and Credibility Assessment (Vol. 9781461455, pp. 173-189). New York, NY: Springer New York. https://doi.org/10.1007/978-1-4614-5547-9_7

Freedman, J. L., Wallington, S. A., \& Bless, E. (1967). Compliance without pressure: The effect of guilt. Journal of Personality and Social Psychology, 7(2, Pt.1), 117-124. https://doi.org/10.1037/h0025009

Gnisci, A., Caso, L., \& Vrij, A. (2010). Have you made up your story? The effect of suspicion and liars' strategies on reality monitoring. Applied Cognitive Psychology, 24(6), 762-773. https://doi.org/10.1002/acp.1584

Goosens, L. (2001). Global versus domain-specific statuses in identity research: a comparison of two self-report measures. Journal of Adolescence, 24(6), 681-699. https://doi.org/10.1006/jado.2001.0438

Gordon, R., Gerrig, R. J., \& Franklin, N. (2009). Qualitative Characteristics of Memories for Real, Imagined, and Media-Based Events. Discourse Processes, 46(1), 70-91. https://doi.org/10.1080/01638530802629117

Granhag, P. A., Andersson, L. O., Strömwall, L. A., \& Hartwig, M. (2004). Imprisoned knowledge: Criminals' beliefs about deception. Legal and Criminological Psychology, 9(1), 103-119. https://doi.org/10.1348/135532504322776889

Granhag, P. A., Stromwall, L. A., \& Jonsson, A.-C. (2003). Partners in Crime: How Liars in 
Collusion Betray Themselves. Journal of Applied Social Psychology, 33(4), 848-868. https://doi.org/10.1111/j.1559-1816.2003.tb01928.x

Hartwig, M., \& Bond, C. (2014). Lie detection from multiple cues: a meta analysis. Applied Cognitive Psychology, 28(5), 661-676. https://doi.org/10.1002/acp.3052

Hartwig, M., Anders Granhag, P., \& Strömwall, L. A. (2007). Guilty and innocent suspects' strategies during police interrogations. Psychology, Crime \& Law, 13(2), 213-227. https://doi.org/10.1080/10683160600750264

Hauch, V., Blandón-Gitlin, I., Masip, J., \& Sporer, S. L. (2015). Are Computers Effective Lie Detectors? A Meta-Analysis of Linguistic Cues to Deception. Personality and Social Psychology Review, 19(4), 307-342. https://doi.org/10.1177/1088868314556539

Hirschberg, J., Benus, S., Brenier, J. M., Enos, F., Friedman, S., Gilman, S., ... Stolcke, A. (2005). Distinguishing Deceptive from Non-Deceptive Speech. Proceedings of Interspeech 2005, 1833-1836. https://doi.org/10.1.1.59.8634

Jansen, A., König, C. J., Stadelmann, E. H., \& Kleinmann, M. (2012). Applicants’ SelfPresentational Behavior. Journal of Personnel Psychology, 11(2), 77-85. https://doi.org/10.1027/1866-5888/a000046

Johnson, M. K., \& Raye, C. L. (1981). Reality monitoring. Psychological Review, 88(1), 6785. https://doi.org/10.1037/0033-295X.88.1.67

Jupe, L. M., Vrij, A., Leal, S., \& Mann, S. (2016). The Lies we Live: Using the Verifiability Approach to Detect Lying about Occupation. Journal of Articles in Support of the Null Hypothesis, 13(1), 1-14.

Kraut, R. E. (1978). Verbal and nonverbal cues in the perception of lying. Journal of Personality and Social Psychology, 36(4), 380-391. https://doi.org/10.1037/00223514.36.4.380

Kraut, R. E., \& Poe, D. B. (1980). Behavioral roots of person perception: The deception 
judgments of customs inspectors and laymen. Journal of Personality and Social Psychology, 39(5), 784-798. https://doi.org/10.1037/0022-3514.39.5.784

Lancaster, G. L. J., Vrij, A., Hope, L., \& Waller, B. (2013). Sorting the Liars from the Truth Tellers: The Benefits of Asking Unanticipated Questions on Lie Detection. Applied Cognitive Psychology. https://doi.org/10.1002/acp.2879

Leal, S., Vrij, A., Mann, S., \& Fisher, R. P. (2010). Detecting true and false opinions: The Devil's Advocate approach as a lie detection aid. Acta Psychologica, 134(3), 323-329. https://doi.org/10.1016/j.actpsy.2010.03.005

Leins, D. A., Fisher, R. P., \& Ross, S. J. (2013). Exploring liars' strategies for creating deceptive reports. Legal and Criminological Psychology. https://doi.org/10.1111/j.20448333.2011.02041.x

Logue, M., Book, A. S., Frosina, P., Huizinga, T., \& Amos, S. (2015). Using reality monitoring to improve deception detection in the context of the cognitive interview for suspects. Law and Human Behavior, 39(4). https://doi.org/10.1037/lhb0000127

Lowe, P. (2006). Counterfeiting: links to organised crime and terrorist funding. Journal of Financial Crime, 13(2), 255-257. https://doi.org/10.1108/13590790610660944

Mac Giolla, E., Granhag, P. A., \& Liu-Jönsson, M. (2013). Markers of good planning behavior as a cue for separating true and false intent. PsyCh Journal, 2(3), 183-189. https://doi.org/10.1002/pchj.36

Masip, J., Sporer, S. L., Garrido, E., \& Herrero, C. (2005). The detection of deception with the reality monitoring approach: a review of the empirical evidence. Psychology, Crime \& Law, 11(1), 99-122. https://doi.org/10.1080/10683160410001726356

McDougall, A. J., \& Bull, R. (2015). Detecting truth in suspect interviews: the effect of use of evidence (early and gradual) and time delay on Criteria-Based Content Analysis, Reality Monitoring and inconsistency within suspect statements. Psychology, Crime \& 
Law, 21(6), 514-530. https://doi.org/10.1080/1068316X.2014.994631

Mead, G. (1967). Mind, self, and society: From the standpoint of a social behaviorist (Works of George Herbert Mead, Vol. 1). (C. Morris, Ed.). Chicago: University of Chicago Press.

Murre, J. M. J., \& Dros, J. (2015). Replication and Analysis of Ebbinghaus' Forgetting Curve. PLOS ONE, 10(7), e0120644. https://doi.org/10.1371/journal.pone.0120644

Nahari, G., \& Pazuelo, M. (2015). Telling a convincing story: Richness in detail as a function of gender and information. Journal of Applied Research in Memory and Cognition, 4(4), 363-367. https://doi.org/10.1016/j.jarmac.2015.08.005

Newman, M. L., Pennebaker, J. W., Berry, D. S., \& Richards, J. M. (2003). Lying Words: Predicting Deception from Linguistic Styles. Personality and Social Psychology Bulletin, 29(5), 665-675. https://doi.org/10.1177/0146167203029005010

Page, M. M. (1981). Demand Compliance in Laboratory Experiments. In J. T. Tedeschi (Ed.), Impression Management Theory and Social Psychological Research (pp. 57-82). New York: Academic Press.

Paravicini, G. (2016). EU's passport fraud “epidemic.” Retrieved April 10, 2018, from https://www.politico.eu/article/europes-fake-forged-stolen-passport-epidemic-visa-freetravel-rights/

Pennebaker, J. W., \& Chew, C. H. (1985). Behavioral inhibition and electrodermal activity during deception. Journal of Personality and Social Psychology, 49(5), 1427-1433. https://doi.org/10.1037/0022-3514.49.5.1427

Pennebaker, J. W., Boyd, R. L., Jordan, K., \& Blackburn, K. (2015). The Development and Psychometric Properties of LIWC2015. Retrieved from https://repositories.lib.utexas.edu/handle/2152/31333

Reinhard, M.-A., Scharmach, M., \& Müller, P. (2013). It's not what you are, it's what you 
know: experience, beliefs, and the detection of deception in employment interviews. Journal of Applied Social Psychology, 43(3), 467-479. https://doi.org/10.1111/j.15591816.2013.01011.x

Roos Af Hjelmsäter, E., Öhman, L., Granhag, P. A., \& Vrij, A. (2014). “Mapping” deception in adolescents: Eliciting cues to deceit through an unanticipated spatial drawing task. Legal and Criminological Psychology, 19(1). https://doi.org/10.1111/j.20448333.2012.02068.x

Salter, M. B. (2004). Passports, mobility, and security: How smart can the border be? International Studies Perspectives. https://doi.org/10.1111/j.1528-3577.2004.00158.x

Sartori, G., Agosta, S., Zogmaister, C., Ferrara, S. D., \& Castiello, U. (2008). How to accurately detect autobiographical events. Psychological Science. https://doi.org/10.1111/j.1467-9280.2008.02156.x

Shaw, D. J., Vrij, A., Leal, S., Mann, S., Hillman, J., Granhag, P. A., \& Fisher, R. P. (2013). Expect the Unexpected? Variations in Question Type Elicit Cues to Deception in Joint Interviewer Contexts. Applied Cognitive Psychology. https://doi.org/10.1002/acp.2911

Sirotich, M. (2007). ePassport Security Under the Microscope. The Second Workshop on the Social Implications of National Security, 257-280. Retrieved from http://ro.uow.edu.au/commpapers/2985/

Sooniste, T., Granhag, P. A., Knieps, M., \& Vrij, A. (2013). True and false intentions: asking about the past to detect lies about the future. Psychology, Crime \& Law, 19(8), 673-685. https://doi.org/10.1080/1068316X.2013.793333

Sporer, S. L., \& Schwandt, B. (2006). Paraverbal indicators of deception: A meta-analytic synthesis. Applied Cognitive Psychology. https://doi.org/10.1002/acp.1190

Sporer, S. L., \& Schwandt, B. (2007). Moderators of nonverbal indicators of deception: A meta-analytic synthesis. Psychology, Public Policy, and Law, 13(1), 1-34. 
https://doi.org/10.1037/1076-8971.13.1.1

Sporer, S. L., \& Sharman, S. J. (2006). Should I believe this? Reality monitoring of accounts of self-experienced and invented recent and distant autobiographical events. Applied Cognitive Psychology, 20(6), 837-854. https://doi.org/10.1002/acp.1234

Staub, E. (1978). Positive social behavior and morality. Volume 1, Social and personal influences. New York: Academic Press, Inc.

Tan, F. T. C., Guo, Z., Cahalane, M., \& Cheng, D. (2016). Developing business analytic capabilities for combating e-commerce identity fraud: A study of Trustev's digital verification solution. Information and Management, 53(7), 878-891. https://doi.org/10.1016/j.im.2016.07.002

Thakur, G. (2017). A Bayesian algorithm for detecting identity matches and fraud in image databases, (April), 1-7. Retrieved from http://arxiv.org/abs/1706.06230

Vrij, A. (2008). Detecting Lies and Deceit: Pitfalls and opportunities. Chichester: Wiley.

Vrij, A. (2014). Interviewing to detect deception. European Psychologist. https://doi.org/10.1027/1016-9040/a000201

Vrij, A. (2015). Verbal Lie Detection Tools: Statement Validity Analysis, Reality Monitoring and Scientific Content Analysis. In P. A. Granhag, A. Vrij, \& B. Verschuere (Eds.), Detecting Deception: Current Challenges and Cognitive Approaches (pp. 1-35).

Chichester, UK: John Wiley \& Sons, Ltd. https://doi.org/10.1002/9781118510001.ch1

Vrij, A., \& Granhag, P. A. (2012). Eliciting cues to deception and truth: What matters are the questions asked. Journal of Applied Research in Memory and Cognition, 1, 110-117. doi.org/10.1016/j.jarmac.2012.02.004

Vrij, A., \& Granhag, P. A. (2014). Eliciting information and detecting lies in intelligence interviewing: An overview of recent research. Applied Cognitive Psychology, 28(6). https://doi.org/10.1002/acp.3071 
Vrij, A., Fisher, R. P., \& Blank, H. (2017). A cognitive approach to lie detection: A metaanalysis. Legal and Criminological Psychology, 22(1), 1-21. https://doi.org/10.1111/lcrp.12088

Vrij, A., Fisher, R., Mann, S., \& Leal, S. (2008). A cognitive load approach to lie detection. Journal of Investigative Psychology and Offender Profiling, 5(1-2), 39-43. https://doi.org/10.1002/jip.82

Vrij, A., Granhag, P. A., Mann, S., \& Leal, S. (2011). Lying about flying: the first experiment to detect false intent. Psychology, Crime \& Law, 17(7), 611-620. https://doi.org/10.1080/10683160903418213

Vrij, A., Leal, S., Mann, S., Fisher, R. P., Dalton, G., Jo, E., ... Houston, K. (2018). Using unexpected questions to elicit information and cues to deceit in interpreter-based interviews. Applied Cognitive Psychology, 32(1), 94-104. https://doi.org/10.1002/acp.3382

Vrij, A., Leal, S., Granhag, P. A., Mann, S., Fisher, R. P., Hillman, J., \& Sperry, K. (2009). Outsmarting the liars: The benefit of asking unanticipated questions. Law and Human Behavior, 33(2), 159-166. https://doi.org/10.1007/s10979-008-9143-y

Vrij, A., Leal, S., Mann, S. A., \& Granhag, P. A. (2011). A comparison between lying about intentions and past activities: Verbal cues and detection accuracy. Applied Cognitive Psychology. https://doi.org/10.1002/acp.1665

Vrij, A., Mann, S., Leal, S., \& Fisher, R. (2012). Is anyone there? Drawings as a tool to detect deceit in occupation interviews. Psychology, Crime \& Law, 18(4), 377-388. https://doi.org/10.1080/1068316X.2010.498422

Vrij, A., Mann, S., Leal, S., \& Granhag, P. A. (2010). Getting into the Minds of Pairs of Liars and Truth Tellers: An Examination of Their Strategies !2010-04-16 !2010-0512 !2010-06-24 ! The Open Criminology Journal, 3(2), 17-22. 
https://doi.org/10.2174/1874917801003020017

Vrij, A., Mann, S., Leal, S., Vernham, Z., \& Vaughan, M. (2016). Train the Trainers: A First Step towards a Science-Based Cognitive Lie Detection Training Workshop Delivered by a Practitioner. Journal of Investigative Psychology and Offender Profiling, 13(2), 110 130. https://doi.org/10.1002/jip.1443

Vrij, A., Taylor, P., \& Picornell, I. (2015). Verbal Lie Detection. In G. Oxburgh, T. Myklebust, T. Grant, \& R. Milne (Eds.), Communication in investigative and legal contexts: Integrated approaches from forensic psychology, linguistics and law enforcement. (pp. 259-287). Chichester: John Wiley \& Sons, Ltd.

Walczyk, J. J., Igou, F. P., Dixon, A. P., \& Tcholakian, T. (2013). Advancing Lie Detection by Inducing Cognitive Load on Liars: A Review of Relevant Theories and Techniques Guided by Lessons from Polygraph-Based Approaches. Frontiers in Psychology, 4, 14. https://doi.org/10.3389/fpsyg.2013.00014

Walker, W. R., Skowronski, J. J., \& Thompson, C. P. (2003). Life is pleasant--and memory helps to keep it that way! Review of General Psychology, 7(2), 203-210. https://doi.org/10.1037/1089-2680.7.2.203

Walker, W. R., Vogl, R. J., \& Thompson, C. P. (1997). Autobiographical memory: unpleasantness fades faster than pleasantness over time. Applied Cognitive Psychology, 11(5), 399-413. https://doi.org/10.1002/(SICI)1099-0720(199710)11:5<399::AIDACP462>3.0.CO;2-E

Wang, G., Chen, H., \& Atabakhsh, H. (2004). Criminal identity deception and deception detection in law enforcement. Group Decision and Negotiation. https://doi.org/10.1023/B:GRUP.0000021838.66662.0c

Warmelink, L., Vrij, A., Mann, S., \& Granhag, P. A. (2013). Spatial and Temporal Details in Intentions: A Cue to Detecting Deception. Applied Cognitive Psychology, 27(1), 101- 
106. https://doi.org/10.1002/acp.2878

Warmelink, L., Vrij, A., Mann, S., Jundi, S., \& Granhag, P. A. (2012). The effect of question expectedness and experience on lying about intentions. Acta Psychologica. https://doi.org/10.1016/j.actpsy.2012.07.011

Weiss, B., \& Feldman, R. S. (2006). Looking Good and Lying to Do It: Deception as an Impression Management Strategy in Job Interviews. Journal of Applied Social Psychology, 36(4), 1070-1086. https://doi.org/10.1111/j.0021-9029.2006.00055.x

Yarkoni, T. (2009). Big Correlations in Little Studies. Perspectives on Psychological Science, 4(3), 294-298. https://doi.org/10.1111/j.1745-6924.2009.01127.x

Zhou, L., Burgoon, J. K., Nunamaker, J. F., \& Twitchell, D. (2004). Automating LinguisticsBased Cues for detecting deception in text-based asynchronous computer-mediated communication. Group Decision and Negotiation, 13(1), 81-106. https://doi.org/10.1023/B:GRUP.0000011944.62889.6f

Zill, O. (2002). Crossing Borders: How Terrorists Use Fake Passports, Visas and Other Identity Documents. Frontline. Retrieved from http://www.pbs.org/wgbh/pages/frontline/shows/trail/etc/fake.html

Zipf, G. K. (1949). Human Behavior and the Principle of Least Effort. Addisson-Wesley Press, Cambridge, 573. https://doi.org/10.1002/1097-4679(195007)6:3<306::AIDJCLP2270060331>3.0.CO;2-7

Zuckerman, M., Depaulo, B. M., \& Rosenthal, R. (1981). Verbal and nonverbal communication of deception. Advances in Experimental Social Psychology, 14(C), 159. https://doi.org/10.1016/S0065-2601(08)60369-X 
Table 1

MANOVA results for each of the outcome question and process question word count dependent variables.

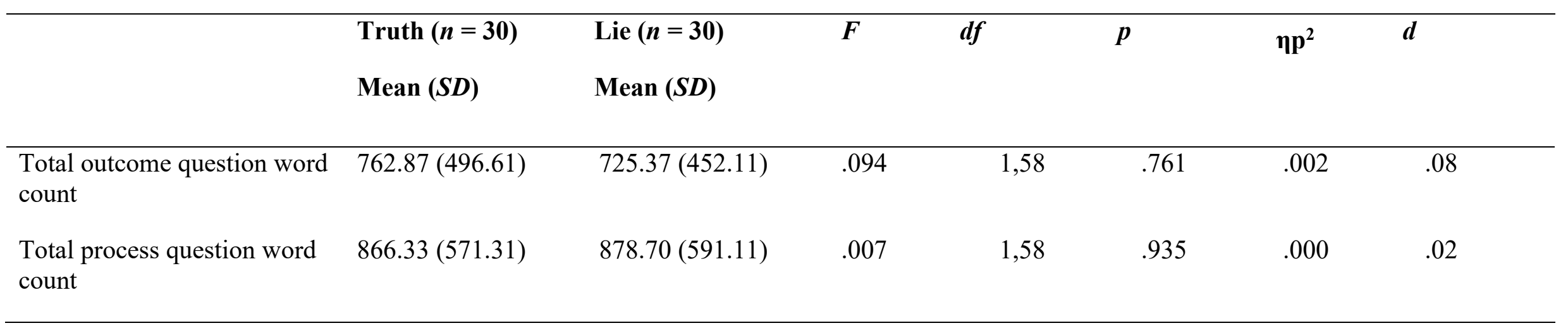


MANOVA results for each of the RM dependent variables.

\begin{tabular}{llllllll}
\hline & Truth $(\boldsymbol{n}=\mathbf{3 0})$ & Lie $(\boldsymbol{n}=\mathbf{3 0})$ & $\boldsymbol{F}$ & $\boldsymbol{d f}$ & $\boldsymbol{p}$ & $\boldsymbol{\eta p}^{2}$ & $\boldsymbol{d}$ \\
& Mean $(\boldsymbol{S D})$ & Mean $(\boldsymbol{S D})$ & & & & \\
& & & & & & \\
\hline Perceptual details & $425.50(287.60)$ & $388.63(178.32)$ & .356 & 1,58 & .553 & .006 & .15 \\
Temporal details & $48.70(30.06)$ & $43.60(33.20)$ & .384 & 1,58 & .538 & .007 & .16 \\
Spatial details & $22.33(18.27)$ & $28.13(21.25)$ & 1.285 & 1,58 & .262 & .022 & .29 \\
\hline
\end{tabular}

Table 3 
MANOVA results for each of the RM dependent variables as a function of Question Type

\begin{tabular}{llllllll}
\hline & Process & Outcome & $\boldsymbol{F}$ & $\boldsymbol{d f}$ & $\boldsymbol{p}$ & $\boldsymbol{\eta p}^{2}$ & $\boldsymbol{d}$ \\
& Mean $($ SD) & Mean $($ SD) & & & & \\
& & & & & & \\
\hline Perceptual details & $209.96(110.63)$ & $188.81(117.11)$ & 8.924 & 1,56 & .004 & .137 & .18 \\
Temporal details & $23.03(15.57)$ & $23.75(17.14)$ & .485 & 1,56 & .489 & .009 & .04 \\
Spatial details & $12.81(10.22)$ & $13.21(10.64)$ & .190 & 1,56 & .665 & .003 & .03 \\
\hline
\end{tabular}

Table 4

MANOVA results for each of the language dependent variables. 


\begin{tabular}{|c|c|c|c|c|c|c|c|}
\hline & $\begin{array}{l}\text { Truth }(n=30) \\
\text { Mean }(S D)\end{array}$ & $\begin{array}{l}\text { Lie }(n=30) \\
\text { Mean }(S D)\end{array}$ & $F$ & $d f$ & $p$ & $\eta p^{2}$ & $d$ \\
\hline Total positive emotion words & $3.08(.75)$ & $3.49(.81)$ & 4.15 & 1,58 & $.046^{*}$ & .067 & .53 \\
\hline $\begin{array}{l}\text { Total negative emotion } \\
\text { words }\end{array}$ & $1.36(.59)$ & $1.37(.63)$ & .041 & 1,58 & .841 & .001 & .01 \\
\hline $\begin{array}{l}\text { Total cognitive process } \\
\text { words }\end{array}$ & $16.58(2.40)$ & $15.40(1.95)$ & 4.38 & 1,58 & $.043 *$ & .069 & .54 \\
\hline Total cause words & $2.22(.65)$ & $1.87(.66)$ & 4.02 & 1,58 & .063 & .059 & .53 \\
\hline
\end{tabular}

$* p<.05$

Table 5

MANOVA results for each of the language dependent variables as a function of Question Type 


\begin{tabular}{|c|c|c|c|c|c|c|c|}
\hline & $\begin{array}{l}\text { Process } \\
\text { Mean }(S D)\end{array}$ & $\begin{array}{l}\text { Outcome } \\
\text { Mean (SD) }\end{array}$ & $F$ & $d f$ & $p$ & $\eta p^{2}$ & $d$ \\
\hline Positive emotion words & $3.14(.93)$ & $3.43(1.00)$ & 4.178 & 1,58 & $.046 *$ & .067 & .30 \\
\hline Negative emotion words & $1.29(.70)$ & $1.45(.63)$ & 4.783 & 1,58 & $.033 *$ & .076 & .24 \\
\hline Cognitive process words & $16.36(2.50)$ & $15.55(2.49)$ & 9.579 & 1,58 & $.003 * *$ & .142 & .32 \\
\hline Cause words & $2.31(.86)$ & $1.71(.71)$ & 33.554 & 1,58 & $<.001 * * *$ & .366 & .76 \\
\hline
\end{tabular}

$* p<.05 ; * * p<.005 ; * * * p<.001$ 


\section{Appendix A}

1a) What is it about this role that interests you?

1b) What potential issues or stumbling blocks did you think you may face as part of this interview and what considerations have you made about how you would overcome these?

2a) Can you describe for me an incident during your education or previous employment where you let yourself down?

2b) How did this incident affect your relationship at the time with your boss/ fellow students / supervisor/ and/or co-workers?

3a) What relevant background knowledge and/or experience do you have for this job?

3b) How did you come to acquire this knowledge/ experience?

4a) What was your greatest weakness in your previous job or most recent education?

4b) How did you manage to compensate for this weakness? What strategies did you use overcome this?

5a) What was your greatest strength in your previous job or most recent education?

5b) Was there a particular experience, which demonstrated this strength, and how did you use it to achieve a goal or solution?

6a) What was the most 'difficult' social aspect of your most recent job or recent education?

6b) How did this situation evolve into being and how exactly did this incident affect your relationship with your co-workers / fellow students?

7a) What was your last disagreement at work or university concerning?

7b) How did you practically overcome the friction caused (i.e. resolve the issue)?

8a) Where do you aspire to be/ see yourself in 2 years' time?

8b) How have 2-3 notable events, over the last few years, influenced these career aspirations? 